\title{
Michael Wenzel (dir.), Die Gemälde der Herzog August Bibliothek
}

catalogue d'exposition, Wiesbaden : Harrassowitz Verlag (Wolfenbütteler Forschungen, 133), 2012, 591 p., $168 €$

\section{Axelle Chassagnette}

\section{Q OpenEdition}

\section{Journals}

Édition électronique

URL : http://journals.openedition.org/ifha/7559

DOI : 10.4000/ifha.7559

ISSN : 2198-8943

Éditeur

IFRA - Institut franco-allemand (sciences historiques et sociales)

Référence électronique

Axelle Chassagnette, « Michael Wenzel (dir.), Die Gemälde der Herzog August Bibliothek », Revue de l'IFHA [En ligne], Date de recension, mis en ligne le 13 décembre 2013, consulté le 22 septembre 2020. URL http://journals.openedition.org/ifha/7559; DOI : https://doi.org/10.4000/ifha.7559

Ce document a été généré automatiquement le 22 septembre 2020

(CIFHA 


\section{Michael Wenzel (dir.), Die Gemälde der Herzog August Bibliothek}

catalogue d'exposition, Wiesbaden : Harrassowitz Verlag (Wolfenbütteler Forschungen, 133), 2012, 591 p., $168 €$

\section{Axelle Chassagnette}

Ce catalogue, rédigé sous la direction de $\mathrm{M}$. Wenzel, présente des objets que ne recherchent pas habituellement les lecteurs de la bibliothèque de Wolfenbüttel: il s'agit de la collection de peintures en possession de l'institution, qui a fait l'objet d'une exposition et d'un catalogue en 2012, en même temps que d'un premier inventaire complet. Cet ensemble, usuellement dispersé dans et sur les murs de la bibliothèque, comprend 150 œuvres. L'ouvrage lui consacre une longue introduction historique suivi d'un catalogue très détaillé. Ce dernier présente également des œuvres étrangères à la bibliothèque mais qui peuvent être mises en relation étroite avec les objets inventoriés. Il s'agit surtout de productions de l'époque moderne, du XVI ${ }^{\mathrm{e}}$ au XVIII ${ }^{\mathrm{e}}$ siècle, et en grande majorité de portraits de savants, de réformateurs et de membres de la famille ducale de Brunswick, ainsi que de quelques sujets historiques, vues de villes et représentations allégoriques. La plupart sont d'acquisition assez tardive dans l'histoire des collections de Wolfenbüttel. Si l'on sait en effet qu'il existait, depuis l'Antiquité et de manière fréquente dans la première modernité européenne, une tradition d'association des bibliothèques à l'exposition d'objets d'art et de curiosité, la collection de livres enrichie par Auguste le Jeune de Brunswick-Lunebourg (1579-1666) était encore dissociée des objets d'art qu'il possédait par ailleurs. En 1661, Hermann Conring, professeur à l'université d'Helmstedt et conseiller d'Auguste, compose un panégyrique de la bibliothèque: il $\mathrm{y}$ rappelle la tradition d'ornementation des espaces des bibliothèques, mais loue celle de Wolfenbüttel pour s'y être soustraite - car cette habitude, dit-il, sert l'orgueil humain plutôt que l'étude, véritable but de l'institution. Ce n'est qu'au début du XVIII ${ }^{\mathrm{e}}$ siècle que l'on trouve la trace d'une acquisition systématique d'œuvres peintes, notamment de portraits. C'est alors le règne d'Anton Ulrich (1633-1714), le second fils d'Auguste, et la bibliothèque est dirigée par Gottfried Wilhelm Leibniz (1646-1716). La recherche de portraits peints doit être mise en relation avec la transformation architecturale de la bibliothèque, qui se traduit par la 
construction de la rotonde (Bibliotheksrotunde) à partir de 1705. On peut, à partir de cette période, reconstruire les achats groupés de peintures, qui se font de manière régulière. Dès 1705, Anton Ulrich fait ainsi acquérir aux enchères le Museum Francianum, qui comprend les livres et la collection de portraits du savant et poète néerlandais Pieter de Frans. D'autres œuvres sont acquises de manière isolée, transférées des demeures ducales ou des universités d'Helmstedt puis de Göttingen à la bibliothèque. C'est tardivement, au XIX ${ }^{e}$ siècle, qu'apparaît dans les sources le premier programme écrit d'ornementation de l'institution. On le doit au bibliothécaire Adolf Ebert (1791-1834). Les ébauches, datées des années 1823-1827, associent les portraits des grands réformateurs, de lettrés (philosophes, médecins, naturalistes) et des membres éminents de la famille ducale. Ces sujets restent à l'honneur, avec des réaménagements, dans les nombreuses modifications architecturales et muséales que connait la bibliothèque jusqu'à nos jours.

Ouvrage érudit et richement illustré, ce catalogue permet donc de découvrir un pan méconnu de l'histoire des collections de la Herzog August Bibliothek. En consacrant du temps à la description et à l'analyse de chaque œuvre inventoriée, dont la production et l'acquisition sont toujours soigneusement contextualisées, il aborde cependant des questions plus diverses et plus larges. Il comprend en particulier de nombreux développements sur le genre du portrait, et interroge le sens (notamment politique et confessionnel) de son acquisition et de son exposition dans le temple du savoir que constitue, depuis l'époque moderne, la bibliothèque ducale de Wolfenbüttel.

\section{INDEX}

Index chronologique : Frühe Neuzeit

Thèmes : Lehrbücher/ Einführungen/ Hilfsmittel

\section{AUTEUR}

AXELLE CHASSAGNETTE

université Lyon II 